\title{
Advanced Cardiac Life Support Training
}

\author{
Edward J. Despott ${ }^{\mathrm{a}} \quad$ Florian Schreiber ${ }^{\mathrm{b}}$ \\ ${ }^{a}$ Wolfson Unit for Endoscopy, St Mark's Hospital and Academic Institute, Imperial College, London, UK; \\ ${ }^{b}$ Department of Internal Medicine, Division of Gastroenterology and Hepatology, Medical University of Graz, \\ Graz, Austria
}

\section{Key Words}

Sedation providers • Advanced cardiac life support training • Propofol

\begin{abstract}
The OMED/ESGE consensus statements of the International Symposium on Sedation in Endoscopy, Athens, September 2009, in keeping with guidelines and position statements published by other societies, underline the need for sedation providers to be adequately trained in dealing with scenarios involving patients in respiratory and/or cardiovascular distress. This training should prepare the sedation provider with the necessary acumen to prevent, recognize and remedy sedation-related emergencies. Life support training that adheres to the International Liaison Committee on Resuscitation (ILCOR) guidelines should be a mandatory component of this instruction that should be governed by formal assessment and quality assurance reappraisal.
\end{abstract}

Copyright $\odot 2010$ S. Karger AG, Basel

\section{Introduction}

National guidelines and position statements published to date on sedation in gastrointestinal endoscopy [1-5] concur about the pressing need for the establishment of dedicated, structured training programs for all sedation providers. This view is also supported by the OMED/
ESGE consensus statements of the International Symposium on Sedation in Endoscopy, Athens, September 2009. Published guidelines [1-5] propose that training programs should be multidisciplinary, with the participation of an anesthesiologist, and have a framework containing a core curriculum of didactic sessions, life support (with simulator) training (with a main emphasis on airway management) and a period of preceptorship. The life support components of such programs are critical, considering that up to $50 \%$ of serious adverse events that occur during gastrointestinal endoscopy are sedation-related and that most of these sedation-associated complications are a result of respiratory and/or cardiovascular depression $[6,7]$.

The life support training for sedation providers should ensure training in the prevention, recognition and rescue of patients in respiratory or cardiovascular distress induced by the sedation process itself. The training should also develop the appreciation that the depth of sedation, as described by the American Society of Anesthesiologists (ASA) [8], is a dynamic continuum and that certain patients may be more sensitive to the effects of sedative drugs than others. The incorporation of an understanding of the pharmacology of the various sedative agents in use, taking into account that all sedative agents have the potential of inducing respiratory and/or cardiovascular depression $[8,9]$, would also be an essential part of the preventative aspect of the life support training.

\section{KARGER}

Fax +4161306 1234

E-Mail karger@karger.ch

www.karger.com (c) 2010 S. Karger AG, Basel

$0012-2823 / 10 / 0822-0113 \$ 26.00 / 0$

Accessible online at:

www.karger.com/dig
Edward J. Despott, MD, MRCP

Wolfson Unit for Endoscopy, St Mark's Hospital and Academic Institute Imperial College London, Watford Road

London HA1 3UJ (UK)

Tel. +44 2082354 136, Fax +442084233 588, E-Mail edespott@ doctors.org.uk 


\section{Life Support Training}

At the OMED/ESGE Athens International Symposium on Sedation, the minimum level of life support training required of health care professionals involved in the provision of sedation for gastrointestinal endoscopy was debated at length. This debate mainly revolved around the minimum level of training required by the personnel who are actually present in the room where sedation is being administered. In conclusion, there was strong consensus among the delegates that the minimum requirement is that all health care professionals involved in the delivery of sedation must be able to provide basic life support, on condition that a provider of advanced cardiac life support is immediately available if further intervention is required. During procedures involving the use of propofol sedation, there was unanimous agreement that at least one of the personnel present in the room where the propofol sedation is being administered must be trained in advanced cardiac life support. This position statement is supportive of similar statements made in guidelines and consensus reports published by other joint societies and institutions to date $[1-5,8]$.

There was undisputed consensus that life support training must conform to the International Consensus on Cardiopulmonary Resuscitation (CPR) and Emergency Cardiovascular Care (ECC) Science with Treatment Recommendations (CoSTR), $2005[10,11]$ as published by the American Heart Association [10] and the European
Resuscitation Council [11] on behalf of the International Liaison Committee on Resuscitation (ILCOR). In keeping with this, life support training should follow the universal cardiac life support algorithm and the approved guidelines of the local governing resuscitation societies to cover training in airway management, venous access, the administration of drugs (including reversal agents where appropriate) and the application of cardiac defibrillation.

As respiratory depression and airway compromise remain the most commonly encountered adverse events relating to sedation, any life support training dedicated to sedation providers should also facilitate strong emphasis on basic and advanced airway management instruction by an anesthesiologist. This should include training in basic techniques, such as the jaw thrust and chin lift maneuvers and placement of oropharyngeal and nasopharyngeal airways, and more advanced techniques, including bag-mask ventilation and laryngeal mask airway placement [8]. The enhanced airway training should be in line with the guidelines set out by national and international anesthesiology institutions $[8,12]$.

In conclusion, successful completion of such training programs should become mandatory prerequisites for healthcare professionals involved in the administration of propofol sedation in particular. Competency should be formally assessed and documented at the time of initial granting of privileges, it should also be constantly monitored through quality assurance programs and reassessed at regular intervals.

\section{References}

1 Byrne MF, Chiba N, Singh H, Sadowski DC: Propofol use for sedation during endoscopy in adults: a Canadian Association of Gastroenterology position statement. Can J Gastroenterol 2008;22:457-459.

2 Cohen LB, Delegge MH, Aisenberg J, Brill JV, Inadomi JM, Kochman ML, Piorkowski JD Jr: AGA Institute review of endoscopic sedation. Gastroenterology 2007;133:675-701.

-3 Riphaus A, Wehrmann T, Weber B, Arnold J, Beilenhoff U, Bitter H, von DS, Domagk D, Ehlers AF, Faiss S, Hartmann D, Heinrichs W, Hermans ML, Hofmann C, In der SS, Jung M, Kahler G, Kraus M, Martin J, Meining A, Radke J, Rosch T, Seifert H, Sieg A, Wigginghaus B, Kopp I: S3 Guideline: sedation for gastrointestinal endoscopy 2008. Endoscopy 2009;41:787-815.

-4 Schreiber F, Working Group on Endoscopy, Austrian Society of Gastroenterology and Hepatology (OGGH): Austrian Society of Gastroenterology and Hepatology (OGGH)
- guidelines on sedation and monitoring during gastrointestinal endoscopy. Endoscopy 2007;39:259-262.

5 Vargo JJ, Cohen LB, Rex DK, Kwo PY: Position statement: Nonanesthesiologist administration of propofol for GI endoscopy. Gastroenterology 2009;137:2161-2167.

-6 Eisen GM, Baron TH, Dominitz JA, Faigel DO, Goldstein JL, Johanson JF, Mallery JS, Raddawi HM, Vargo JJ, Waring JP, Fanelli RD, Wheeler-Harbough J: Complications of upper GI endoscopy. Gastrointest Endosc 2002;55:784-793.

7 Petrini J, Egan JV: Risk management regarding sedation/analgesia. Gastrointest Endosc Clin N Am 2004; 14:401-414.

$>8$ Practice guidelines for sedation and analgesia by non-anesthesiologists. A report by the American Society of Anesthesiologists Task Force on Sedation and Analgesia by NonAnesthesiologists. Anesthesiology 1996;84: 459-471.
9 Hausman LM, Reich DL: Providing safe sedation/analgesia: an anesthesiologist's perspective. Gastrointest Endosc Clin N Am 2008;18:707-716, viii.

10 Zaritsky A, Morely PT: The evidence evaluation process for the 2005 International Consensus Conference on Cardiopulmonary Resuscitation and Emergency Cardiovascular Care Science with treatment recommendations. Circulation 2005;112:III-1-III136 .

11 International Liaison Committee on Resuscitation: Advanced life support. Resuscitation: 2005;67:213-247.

12 Reed PA: Airway management for the uninitiated. Gastrointest Endosc Clin N Am 2008; 18:773-782, viii. 